\begin{tabular}{ll|l} 
Case Reports in & \multicolumn{2}{c}{ Case Rep Gastroenterol 2013;7:428-432 } \\
\cline { 2 - 3 } Gastroenterology & $\begin{array}{l}\text { DOI: 10.1159/000355879 } \\
\text { Published online: October 5, 2013 }\end{array}$ & $\begin{array}{l}\text { ○ 2013 S. Karger AG, Basel } \\
\text { www.karger.com/crg }\end{array}$ \\
\hline & $\begin{array}{l}\text { This is an Open Access article licensed under the terms of the Creative Commons } \\
\text { Attribution-NonCommercial 3.0 Unported license (CC BY-NC) (www.karger.com/OA- } \\
\text { license), applicable to the online version of the article only. Distribution permitted for non- } \\
\text { commercial purposes only. }\end{array}$
\end{tabular}

\title{
A Retroperitoneal Bronchogenic Cyst Mimicking a Pancreatic or Adrenal Mass
}

\author{
Tina Runge $^{a} \quad$ Annika Blank $^{b} \quad$ Stephan C. Schäfer ${ }^{b} \quad$ Daniel Candinas ${ }^{a}$ \\ Beat Gloor ${ }^{a} \quad$ Eliane Angst ${ }^{a}$ \\ ${ }^{a}$ Department of Visceral Surgery and Medicine, Inselspital, and ${ }^{b}$ University of Bern and \\ Institute of Pathology, University of Bern, Bern, Switzerland
}

\section{Key Words}

Retroperitoneal · Bronchogenic cyst · Embryology · Adrenal mass · Cystic tumor

\begin{abstract}
Retroperitoneal location of bronchogenic cysts is extremely rare. Most commonly they are encountered in the posterior mediastinum. Bronchogenic cysts arise from developmental aberrations of the tracheobronchial tree in the early embryologic period. We report a 42-year-old female patient with a retroperitoneal bronchogenic cyst in the left adrenal region. She was admitted to our hospital with epigastric pain and subsequently underwent CT of the abdomen. The examination revealed a mass related to the left adrenal gland. Endocrine tests for adrenal hypersecretion were negative. Because of the uncertain entity, laparoscopic adrenalectomy was performed. Pathological examination revealed a bronchogenic cyst in proximity to an inconspicuous left adrenal gland. Although very rare, bronchogenic cysts should be considered in the differential diagnosis of retroperitoneal cystic lesions and surgical resection pursued for symptom resolution and to establish a definitive histology.
\end{abstract}

(c) 2013 S. Karger AG, Basel

\section{Introduction}

Bronchogenic cysts are rare developmental aberrations of the primitive foregut which occur between the third and the seventh week of embryonic life, through abnormal budding. Depending on the location of the abnormal budding they are associated to cervical [1], thoracic or abdominal [2] structures. Often the tracheobronchial tree is affected. Therefore the most common location of bronchogenic cysts is the posterior mediastinum; retroperito-

Prof. Beat Gloor

Department of Visceral Surgery and Medicine, Inselspital

$\mathrm{CH}-3010$ Bern (Switzerland)

E-Mail beat.gloor@insel.ch 
Runge et al.: A Retroperitoneal Bronchogenic Cyst Mimicking a Pancreatic or Adrenal Mass

neal location is rare. The exact mechanism is not yet known. It has been postulated that the aberrant bud detaches from the primitive foregut, then migrates towards the abdomen prior to the fusion of the diaphragm, resulting in a retroperitoneal bronchogenic cyst $[3,4]$. Symptoms include epigastric or back pain, but most patients are asymptomatic. Typically all laboratory and especially endocrine test results are normal. The differential diagnosis includes adrenal adenomas, pancreatic cysts and pseudocysts, mucinous cyst adenomas, pseudopapillary neoplasms, cystic teratomas and urogenital cysts. The final diagnosis is usually made by histological analysis. As patients are mostly asymptomatic, most cases are diagnosed incidentally. The indication for surgery is controversial in these cases, but the uncertainty of the diagnosis after imaging supports the indication for surgery and histological workup.

\section{Case Report}

A 42-year-old woman was admitted to the hospital with sharp continuous epigastric pain of 2 months duration with postprandial augmentation. She denied any other gastrointestinal symptoms or weight loss. Her medical and surgical history was insignificant beside psoriasis and smoking. She had neither a history of previous pancreatitis nor hypertension or clinical signs for hypercortisolism, but irregular vaginal bleedings. Physical examination was normal, with a BMI of $25.6 \mathrm{~kg} / \mathrm{m}^{2}$. Serum laboratory tests showed signs of inflammation and a CT scan of the abdomen (fig. 1) showed a cystic mass of $5 \times 3.6 \times 4 \mathrm{~cm}$ located adjacent to the pancreatic tail and left adrenal gland. She was treated with antibiotics. Endoscopic ultrasonography with fine needle aspiration was performed and showed a polycystic structure with anechoic and hyperechoic portions. Microbiological analysis and analysis for lipase were negative. There were no malignant cells, but carcinoembryonic antigen (CEA) was elevated with 3,777 $\mu \mathrm{g} / \mathrm{l}$ (normal <5) in the cyst, but normal in the serum with $4.3 \mu \mathrm{g} / \mathrm{l}$. Because of the association to the adrenal gland and the history of vaginal bleeding, endocrine evaluation for adrenal hypersecretion was performed. All tests were normal, including renin and aldosterone, plasma and urine catecholamines, metanephrines, estradiol, luteinizing hormone, follicle-stimulating hormone and cortisol.

We suspected a cystic adrenal tumor, therefore we performed a diagnostic laparoscopy. The cystic and encapsulated lesion with smooth and clear boundaries was not discriminable from the left adrenal gland. The pancreas, stomach, diaphragm and aorta were adjacent to the cyst, but not involved. The mass was resected laparoscopically with the left adrenal gland. Postoperative recovery was uneventful.

In the pathological workup the cyst had a smooth inner lining and contained a grey viscous mass. Microscopically, it consisted of ciliated, respiratory epithelium, seromucous glands and fully developed cartilage, without any malignant or dysplastic cells (fig. 2). The adrenal gland was histologically inconspicuous and had no direct contact or connection to the cyst.

\section{Discussion}

Bronchogenic cysts are foregut development aberrations in early embryonic life. The most common location is the posterior mediastinum and related to the lung or the tracheobronchial system. When a bronchogenic cyst is located retroperitoneally, the localization in $80 \%$ of published cases is left to the midline and close to the distal pancreas, spleen and left 
Runge et al.: A Retroperitoneal Bronchogenic Cyst Mimicking a Pancreatic or Adrenal Mass

adrenal gland as in the present case [5]. Bronchogenic cysts occur in a wide age range. In the youngest patient affected, the diagnosis of retroperitoneal bronchogenic cyst was made prenatally [6]. The oldest patient affected was 59 years old. Bronchogenic cysts occur with equal frequency in men and women [4]. The pathogenesis is not fully understood, but it was assumed that a lack of closure of the pleuroperitoneal channel in conjunction with abnormal budding from the primitive foregut may lead to migration of tracheobronchial tree bud to the abdominal cavity. Usually bronchogenic cysts are asymptomatic. If the cyst is in relation with the tracheobronchial tree, it causes recurrent respiratory infection. Although most abdominal cases are diagnosed incidentally, they may present with epigastric or back pain. When detected most of them measure $<5 \mathrm{~cm}$, so they are too small to be symptomatic, unless they are secondarily infected or compress neighboring organs. The diameter of the largest retroperitoneal bronchogenic cyst reported was $18 \mathrm{~cm}$ [7]. Our patient presented with epigastric pain and signs of inflammation. This suggests a secondary infection causing the symptoms. The fine needle aspirate of the content was sterile, but this examination was performed after the onset of antibiotic treatment.

To detect a bronchogenic cyst, CT scan and MRI are the best imaging modalities. In the CT scan the lesions are mixed cystic-solid, sharply defined, hypoattenuating and homogenous possibly with calcifications. In T2-weighted MRI the cyst shows an extremely bright signal. These features are shared with other possible pathological entities: adrenal adenomas, pancreatic cysts and pseudocysts, mucinous cystadenomas, pseudopapillary neoplasms, cystic teratomas, urogenital cysts, epidermoid cysts, cystic type of lymphangioma or stromal tumors. Because of the close anatomical localization to the pancreas and the differential diagnosis of several pancreatic cystic lesions, we used endoscopic ultrasound and fine needle aspiration as a diagnostic step. For pancreatic cystic lesions, the information about the presence of malignant cells, mucus, lipase, CEA and CA19-9 help to decide whether surgery is indicated. In our patient, CEA was elevated in the cyst and normal in the serum. Normal bronchial mucus contains high levels of CEA. As bronchogenic cysts contain a lot of mucus, it is consistent that they contain CEA, as in our case. Very rarely the CEA can be measured systemically [8], but in most cases there are no specific markers in the serum by which to detect a bronchogenic cyst.

Because of localization close to the adrenal gland, an endocrine differential diagnosis is often considered. Therefore an endocrine workup is often performed; nevertheless it does not help the diagnostic process. Due to the impossibility to exclude the presence of a neoplastic disease, surgery is indicated. Once surgical treatment has been chosen, a laparoscopic approach is state of the art. The postoperative outcome is excellent with no report of recurrence [9]. Potential complications often present at the time of diagnosis are secondary infection, bleeding and compression of adjacent organs [10].

Histologically bronchogenic cysts are defined as the simultaneous presence of ciliated respiratory epithelium, mucinous glands and well-differentiated cartilage. These were seen in our case as well (fig. 2). We did not find smooth muscle cells, which have been found in other cases [2]. Additionally, the cyst's content was probably an old hematoma, which might have occurred at the time of endoscopic fine needle aspiration. The initial CT scan showed a cystic lesion with a density of 6 Hounsfield units (HU). For preoperative planning the CT scan was repeated with an arterial and venous phase. It showed a density of the cyst content of $102 \mathrm{HU}$, which is in accordance with the density of a hematoma. This is in accordance with the hypothesis of bleeding after fine needle aspiration. 
Runge et al.: A Retroperitoneal Bronchogenic Cyst Mimicking a Pancreatic or Adrenal Mass

\section{Conclusion}

Although very rare, bronchogenic cysts should be considered in the differential diagnosis of a retroperitoneal mass, particularly those left to the midline. Surgical removal is recommended to establish the diagnosis. The postoperative outcome is excellent, with no report of recurrence.

\section{References}

1 Newkirk KA, Tassler AB, Krowiak EJ, Deeb ZE: Bronchogenic cysts of the neck in adults. Ann Otol Rhinol Laryngol 2004;113:691-695.

2 Liang MK, Yee HT, Song JW, Marks JL: Subdiaphragmatic bronchogenic cysts: a comprehensive review of the literature. Am Surg 2005;71:1034-1041.

-3 Reichelt 0, Grieser T, Wunderlich H, Moller A, Schubert J: Bronchogenic cyst. A rare differential diagnosis of retroperitoneal tumors. Urol Int 2000;64:216-219.

-4 Sumiyoshi K, Shimizu S, Enjoji M, Iwashita A, Kawakami K: Bronchogenic cyst in the abdomen. Virchows Arch A Pathol Anat Histopathol 1985;408:93-98.

5 Chung JM, Jung MJ, Lee W, Choi S: Retroperitoneal bronchogenic cyst presenting as adrenal tumor in adult successfully treated with retroperitoneal laparoscopic surgery. Urology 2009;73:442.e13-442.e15.

6 Bagolan P, Bilancioni E, Nahom A, Trucchi A, Inserra A, Neri M, Spina V, Giorlandino C: Prenatal diagnosis of a bronchogenic cyst in an unusual site. Ultrasound Obstet Gynecol 2000;15:66-68.

7 Goh BK, Chan HS, Wong WK: A rare case of 'giant' right-sided retroperitoneal bronchogenic cyst. Dig Dis Sci 2004;49:1491-1492.

8 Matsuoka Y, Endo K, Kawamura Y, Yoshida T, Saga T, Watanabe Y, Koizumi M, Nakashima T, Konishi J, Yamaguchi N, et al: Normal bronchial mucus contains high levels of cancer-associated antigens, CA125, CA19-9, and carcinoembryonic antigen. Cancer 1990;65:506-510.

-9 Cai Y, Guo Z, Cai Q, Dai S, Gao W, Niu Y, Li G, Zhang Y: Bronchogenic cysts in retroperitoneal region. Abdom Imaging 2013;38:211-214.

10 Sullivan SM, Okada S, Kudo M, Ebihara Y: A retroperitoneal bronchogenic cyst with malignant change. Pathol Int 1999;49:338-341.
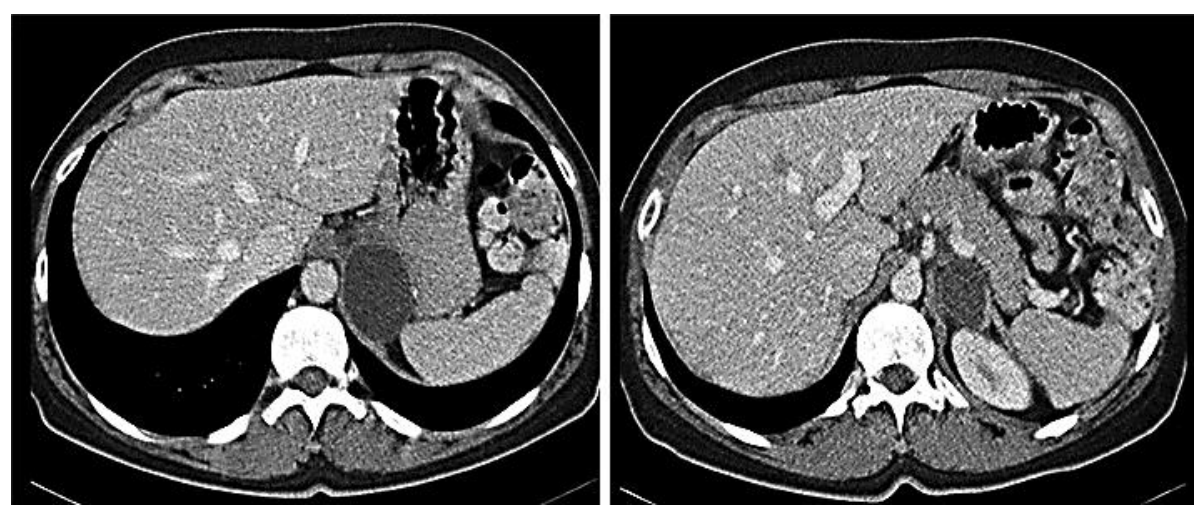

Fig. 1. Axial abdominal CT showing the dense cystic mass in the left suprarenal region adjacent to the pancreas. 


\begin{tabular}{|c|c|c|}
\hline \multirow{3}{*}{$\begin{array}{l}\text { Case Reports in } \\
\text { Gastroenterology }\end{array}$} & \multirow{2}{*}{\multicolumn{2}{|c|}{ Case Rep Gastroenterol 2013;7:428-432 }} \\
\hline & & \\
\hline & DOI: $10.1159 / 000355879$ & $\begin{array}{l}\text { (c) } 2013 \text { S. Karger AG, Basel } \\
\text { www.karger.com/crg }\end{array}$ \\
\hline
\end{tabular}

Runge et al.: A Retroperitoneal Bronchogenic Cyst Mimicking a Pancreatic or Adrenal Mass

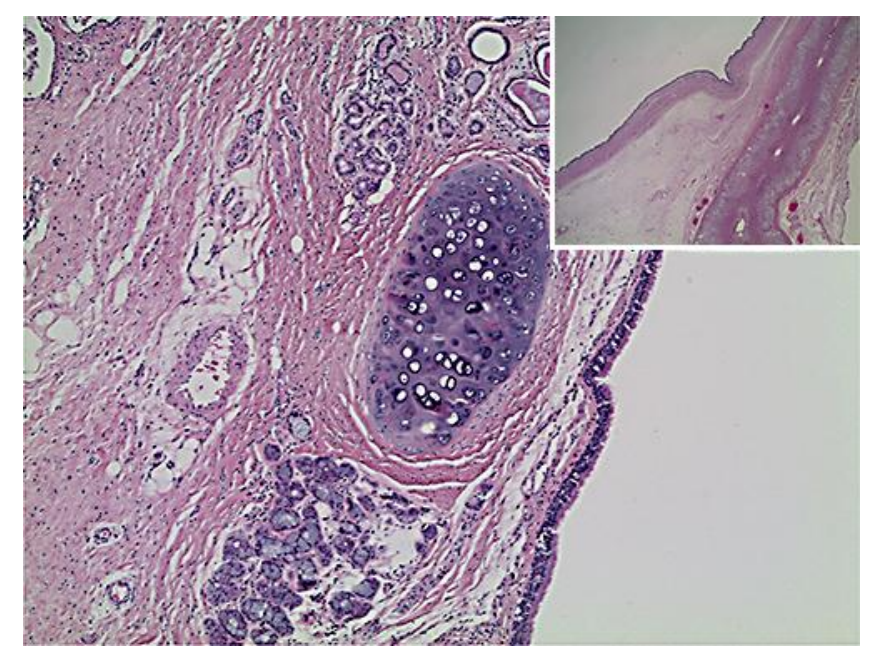

Fig. 2. Microscopic view of the bronchogenic cyst $(\mathrm{HE}, \times 40, \times 10)$. The cyst had a smooth inner lining and contained a grey viscous mass. Microscopically, it consisted of ciliated, respiratory epithelium, seromucous glands and fully developed cartilage, without any malignant or dysplastic cells. 